\title{
A Collaborative Environment for New Learning Ecology and E-Pedagogy
}

\author{
Toshio Okamoto and Mizue Kayama \\ Graduate School of Information Systems, The University of Electro-communications, Japan \\ School of Network and Information, Senshu University, Japan \\ okamoto@ai.is.uec.ac.jp
}

Abstract: Nowadays, we realize change in learning ecology by making progress in Internet technologies and advanced media. A learning ecology moves from individual leaming to collaborative learning via the Internet. So we are urged to create a new e-pedagogy. This paper proposes and discusses functionality for collaborative learning, then discuss what e-pedagogy is, based on new learning ecology. In this discussion, we emphasize the re-use function of data logging occurring during a collaborative learning process. Moreover, we consider the educational meanings and methodology to explore essentials of collaborative learning. We introduce a platform for a collaborative learning environment called RAPSODY-EX (REX) that we have developed. The features and functions of this platform are described, and then we discuss the extendibility of the platform for a collaborative environment from the issue of e-pedagogy we propose.

Key words: e-pedagogy, learning ecology, collaborative learning, knowledge transfer,

\section{INTRODUCTION}

The Internet is becoming a catchphrase in the world of school education, which makes distance education possible to anybody at anytime and from anywhere. As such, a new learning style 'e-Learning' emerged under the new umbrella concept of 'Learning Ecology and Pedagogy', where the Internet raises the level of communications and collaborations among people via technology. Nowadays, the word/system of 'e-Learning' is rapidly spreading due to popularization of the Internet. As for advantages of the 
Internet, people can communicate with each other anytime and anywhere. Moreover people can share, rebuild, stock and reuse various kind of information. Here, it seems that the concept of e-Learning gets citizenship in society instead of CAI (Computer Assisted Instruction). Along with this stream/trend, we recognize the necessity of construction of a new learning society such as learning individuals, learning organization and learning community. Above mentioned, we can say that the Internet is a kind of Treasure Island of educational resources from a worldwide stance, though it includes much harmful information.

\section{PURPOSE OF THIS STUDY}

The aim of this study is to propose the concept of new learning ecology and e-Pedagogy in the center of collaborative learning via the Internet. A learning environment where includes various IT devices and some kinds of computer network (Internet, LAN, WAN, and so on) has produced a new learning ecology such as exploring/discovery learning, collaborative learning and so on. According to these changing situations, a new and persuasive pedagogy has to be created. In this paper the idea of e-pedagogy is proposed. Based on this concept, we introduce the RAPSODY-EX (REX), which is a platform for a collaborative learning environment (Okamoto, Cristea, \& Kayama 2000). A distributed collaborative learning (CL) environment is expected to facilitate learning activities for knowledge building and metacognition through mutual understanding among learners. In this environment, management/integration of the learning resources/information becomes an important task for the purpose of promoting learners' decisionmaking activities and teachers' mentoring activities. The especially stressed functions are as follows: for evaluating learning process, restoring collaborative activities, plug-in API, referring/reusing information and so on.

\section{NEW LEARNING ECOLOGY AND E-PEDAGOGY}

Varieties of knowledge will be taking a form of multimedia in a highly technological, network society. And this knowledge can be obtained through so-called VOD (Video On Demand). Moreover, wide varieties of educational applications and teaching systems will be provided. The problem, however, is that we need the ability to grasp the essence of that knowledge. Also this knowledge should not be enclosed only in a human understanding of the world. An ability to create a new knowledge out of that understanding is now sought. The knowledge in a closed textbook will be 
transferred to this real world. It is important to form live knowledge. To make science and technology attractive to youth needs a synthesizing pipe, that is, a systematic resource to totally canalize the scientific minded to that new knowledge.

In the Post-Modern age, our new learning viewpoint is as follows.

a) Group modeling and collaboration for social activities.

b) Exploration-minded experimental learning.

c) Learning (urged) by asking, explaining and teaching to make a new insight.

d) Interactive diagnosis and open learning model.

From those aspects, we must construct the curriculum with a view for epedagogy based on the following educational considerations:

- Topic oriented structure: contents are synthesized according to topics. Many topics are organized systematically and make comprehensive contents as IT-education.

- Scenario oriented structure: making scenario-like contents and offering well balanced unit subjects.

- Minimum essentials: extracting minimum essential unit subjects as "informatics for all" and making a comprehensive subject together with other common subjects.

- Comprehensive subjects based on existential subjects: an integrated subject, making a comprehensive selection by taking units as thought necessary from other subjects such as math, science and so on.

These are views to make a comprehensive subject. Therefore, it is hard to say what is best. Information technology, however, is a familiar matter so that it should be something attractive to children/ students' mind. It should not be what sounds fictitious.

\section{WHAT IS COLLABORATIVE LEARNING}

\subsection{Some Definitions and facilities}

In terms of what Roschelle \& Teasley defined as "collaboration" to be ".... a coordinated, synchronous activity that is the result of a continued attempt to construct and maintain a shared conception of a problem" (Roschelle \& Teasley 1995). Dillenbourg takes up the following 4 points as the features of $C L$, which are a situation, interactions, process (learning mechanism) and effects of CL (Dillenbourg 1999). Cowie \& Rudduck note that "collaboration in leaning is the opportunity to learn through the 
expression and exploration of diverse ideas and experiences in cooperative company..." (Cowie \& Ruddick 1998). It is not about competing with fellow members of the group and winning, but using the diverse resources available in the group to deepen understanding, sharpen judgment and extend knowledge.

In consideration of those views, Okamoto pointed out that $\mathrm{CL}$ should emphasize 1) process/situated context, 2) individual learning achievement such as knowledge acquisition, skill formation and concept formation, learning set, 3) versatile cognition for both of holistic and serialistic thinking schema, 4) understandings of objective relationships among self/you/he or she, and 5) effects of observation learning (reflection/self-monitoring) (Okamoto et al. 2000). CL doesn't depend on place and time. Especially in an Internet environment, the type of asynchronous ecology of CL is more useful rather than the synchronous one such as a videoconference. Moreover, in the process of CL, individual learning may be sometimes embedded, based on a certain curriculum in schools, and vise versa. Table 1 shows the dimensions on features of CL.

Table 1. The dimensions on features of CL

\begin{tabular}{|c|c|}
\hline Activity-cognitive level & Activity-social level \\
\hline - $\quad$ Discussing & - Observing/Suggesting \\
\hline - $\quad$ Planing/Designing & - Role-taking/Cooperating \\
\hline - Data/Idea sharing & - Coordinaing/Controling \\
\hline - Evaluating/Finding solution & - Social interacting \\
\hline Building knowledge & - Facilitating/Supervising \\
\hline
\end{tabular}

In general, we can divide the activities in collaborative learning into two classes of cognitive level and social level. Based on these activities, the resources required in a CL environment are as follows:

- Technologically mediated dialogue channel

- Shared workplace for a group

- Personal workplace

- Learning materials/ learning tools

- Analyzing tools of data/information

- Learning materials/ learning tools

- Repository/memory for data/information revealed in CL

- Reference channel for the collaborative repository

- Modeling tools for monitoring the process

\subsection{Methods for Supporting Collaborative Activities}

There are two approaches on CSCL. One is to emphasize the interactions among learners. Another is to stress the efficiency of knowledge acquisition 
and the certainty of knowledge acquisition. The former approach aims at clarifying the effect of an interaction and promoting the effect of an interaction as well. There are many researchers focusing on realizing the transparent and seamless purpose of efficient communication. For example, they use agent technology, natural language analysis, statistical text mining and others. The latter approach focuses on providing a medium for the interactions among learners so as to promote and/or increase the efficiency of knowledge acquisition. There are various functions and mechanisms developed for these purposes. In order to support collaborative activities, the following functions are necessary:

- Offering the workspace of an individual and the workspace of a group.

- Supporting mutual transfer data, information and knowledge in the workspaces.

- Including various information media (libraries, applications, tools and so on) to the platform.

- Shared screen image / shared operation.

\section{A PLATFORM FOR THE CL: RAPSODY-EX}

RAPSODY-EX (REX) is a platform of a CL learning environment. Our focus is on the management function for a collaborative workplace in CL. The features of REX are as follows:

- Management of Learning Session: this feature enables a student to participate in collaborative activities on REX.

- The communication library (API) for the shared application/tool: this feature allows plug-in applications/tools for CL (shared applications) to REX.

- The hierarchical control mechanism of learning log data: this feature allows distribution/ record/reference of learning logs based on the learning condition/context.

The main function of this platform is the management of collaborative workplaces and learning sessions (Kayama \& Okamoto 2002, UEC 2004). Once a CL mediator/instructor defines the collaborative activity on REX, a learning session can be generated in REX for the learners. For each learner, a learning session is instantiated on each REX client. A learner expresses his/her opinions/views through shared applications on a learning session. A collaborative workplace, containing two or more learning sessions, keeps and manages the context of CL. The REX server specifically performs the management of a collaborative workplace and a learning session, consisting of some management modules for different information on REX. Moreover, 
it also contains a maintenance module with a set of CL cases and a management module of a learning session

A learning session represents a space for group member activities. Each learning session is generated as a response to the learner's needs / instructional goals on REX. After this, it is registered to the REX server. A learning session contains one or more shared applications representing a unit of $\mathrm{CL}$ activities on REX. A learning session is described by an attribute and a state. The conceptual scheme of a learning session is shown in Figure 1. An attribute is a set of information used for characterizing a learning session. This includes some static information, such as the start time of CL, the participating member of a learning session, the name of a shared application, and a URI (Uniformed Resource Indicator) to the substance of a shared application.

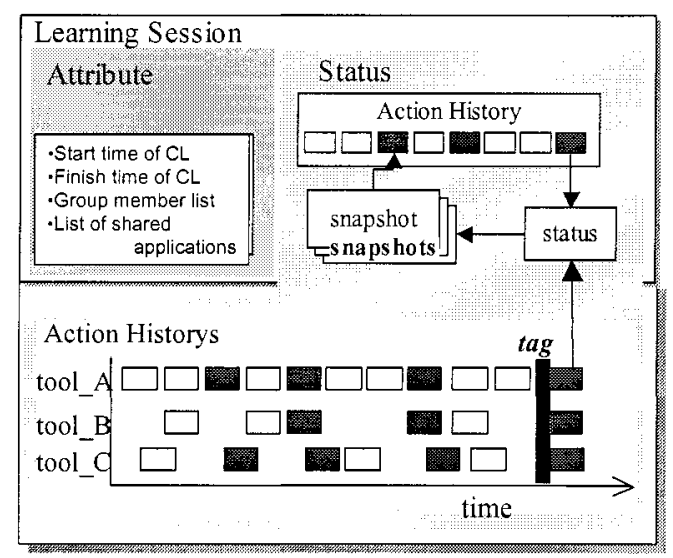

Figure 2. The conceptual scheme of a learning session

The assurance of keeping learning context and the reuse of learning logs are realized by this hierarchical management of learning logs. Additionally, some components of the collaborative environment (eg. shared applications/ tools, and learning management tools for CL) are implemented more easily and effectively. 


\section{MODELING OF COLLABORATIVE ACTIVITIES IN REX}

\subsection{Learning Activities of CL}

Generally, CL by the Internet enables synchronous and asynchronous learning modes. In an asynchronous learning pattern, the communication/ interaction medium consists of an e-mail system, a BBS and others. However in a synchronous learning mode, communication/ interaction among learners is achieved via simultaneous learning tools.

In this research, $C L$ is defined from a different aspect. The simultaneity is emphasized in our case. A synchronized type is defined as an extended case of a synchronized type. Thus, the design principle of REX has to maintain a collaborative workplace. A learning session is an operative object of a collaborative workplace in REX. In this object, the learning activities are expressed as the series of actions for achieving the learning goal. The learning activities for a student are represented as follows:

- $<$ Join $>::=$ acts participating in CL

- $<$ Suspend $::=$ acts which do_not/are_impossible_to contribute to generation of an outcome of $\overline{\mathrm{C}} \mathrm{L}$ although learner has participated in $\mathrm{CL}$.

- $<$ Leave $>::=$ acts which stop the participation for the CL.

- $<$ Refer $>::=$ acts which refer to the outcome and/or the process of CL.

\subsection{Learning States of CL}

The state of $\mathrm{CL}$ is represented by combining four activities: Practicing, Broken, Accomplished and Aborted. The feature of each state is summarized in Table 2.

Table 2. The features of the learning states of $\mathrm{CL}$

\begin{tabular}{|c|c|c|c|c|c|}
\hline \multicolumn{2}{|c|}{ State of Cl } & Practicing & Broken & Accomplished & Aborted \\
\hline \multicolumn{2}{|c|}{ Learning Goal } & NO & $\mathrm{NO}$ & YES & Cannot \\
\hline \multicolumn{2}{|c|}{ Participant } & YES & $\mathrm{NO}$ & $\mathrm{NO}$ & $\mathrm{NO}$ \\
\hline \multirow{4}{*}{$\begin{array}{l}\mathrm{A} \\
\mathrm{C} \\
\mathrm{T} \\
.\end{array}$} & Join & $\mathrm{OK}$ & - & - & - \\
\hline & Suspend & OK & OK & - & - \\
\hline & Leave & $\mathrm{OK}$ & - & OK & $\mathrm{OK}$ \\
\hline & Refer & $\mathrm{OK}$ & OK & OK & $\mathrm{OK}$ \\
\hline
\end{tabular}

A Practicing state in the process is to achieve a learning goal, which is defined as a set of Join mode, Suspend mode and Leave mode. A Broken state in the process is to achieve a learning goal. In this state all of the group members are in Suspend mode. At an Accomplished state, a learning goal is 
achieved. In this state, all of the group members are in Leave mode. At an Aborted state, a learning goal cannot be achieved and any learning activity will not happen. In this state, all of the group members are in Leave mode. Moreover, a Refer state is executed at all learning states.

\subsection{The Functions for Collaborative Modeling by REX}

Some functions are necessary for smooth and efficient interaction/ communication and effective acquisition of some kinds of meta-cognition skills. The first function should be the identification of learning states and learning activities at a collaborative workplace, which offers useful and valuable information for CL support. Thus, the platform can apply some appropriate support for a group/learner.

We assume that it is important to secure the information shared among learners in CL. Shared information here includes result/production/ solution during learning, which are set as attributes of a learning session at REX. Table 3 shows examples of status of a learning session. In this situation, the simultaneity of learning activity is guaranteed. Action is used for the operation/screen_image shared among learners during CL. Action history is used for maintenance of a series of learning activities. Then the information is stored as status of a learning session. Status is held in the result/ production/solution of CL. Therefore information can be offered as a current learning context to a newcomer in CL. Status is also recorded as a snapshot. REX shows a user result/production/solution at the current state. Moreover, REX shows a series of results/productions/solutions by using snapshots. By using this type of information, a learner is able to check the past learning situation for his/her reflection and confirmation. Tag shows integrated learning result of a learning session consisting of some shared applications.

Table 3. The usage of the attributes of a learning session.

\begin{tabular}{l|l|l}
\hline $\begin{array}{l}\text { Granularity } \\
\text { of Log data }\end{array}$ & \multicolumn{2}{|c}{ Synchronous CL } \\
\hline Action & $\begin{array}{l}\text { Operation/Screen sharing } \\
\text { (each shared application) }\end{array}$ & \multicolumn{1}{c}{ Asynchronous CL } \\
\hline $\begin{array}{l}\text { Action } \\
\text { History }\end{array}$ & $\begin{array}{l}\text { Maintaining of Action } \\
\text { (each CL) }\end{array}$ & $\begin{array}{l}\text { Confirmation of a series of Action } \\
\text { (each shared application) }\end{array}$ \\
\hline Status & $\begin{array}{l}\text { Maintaining of results/solutions } \\
\text { Giving a context to a newcomer } \\
\text { (each shared application) }\end{array}$ & \\
\hline Snapshot & Maintaining of results/solutions & $\begin{array}{l}\text { Confirmation of results/solutions } \\
\text { (each shared application) }\end{array}$ \\
\hline Snapshots & $\begin{array}{l}\text { Confirmation/Reflecting of results } \\
\text { Maintaining of contexts } \\
\text { (each shared application) }\end{array}$ & $\begin{array}{l}\text { Confirmation of a series of } \\
\text { results/solutions } \\
\text { (each shared application) }\end{array}$ \\
\hline Tag & $\begin{array}{l}\text { Maintaining of results/solutions } \\
\text { Giving a results to a newcomer }\end{array}$ & $\begin{array}{l}\text { Confirmation of results/solutions } \\
\text { (each learning session) }\end{array}$ \\
\hline
\end{tabular}


(each learning session)

On the other hand, we consider the situation where the simultaneity of learning activities is not guaranteed. In this situation action history, snapshot (s), and tag are also used for supporting CL. Action history is used for a check of a series of action during CL. These actions were previously performed by another group of learners.

Snapshot(s) is used for checking the result/production/solution in learning processes, the learning progress and the change of learning context. A tag is used for examining the results/productions/solutions in learning processes of a learning session.

\section{CONCLUSIONS}

In this paper, we propose e-pedagogy based on new learning ecology and a platform for a collaborative learning environment. First the idea of learning ecology and e-pedagogy are discussed. Then, some fundamental functions of CL are considered. Furthermore REX is shown as an example of the CL platform and the extendibility of this platform is discussed.

In this paper, a CL is considered with the simultaneity of learning activities for achieving a learning goal. Based on the proposed e-pedagogy, the learning activities in $\mathrm{CL}$ are examined and the model for $\mathrm{CL}$ was discussed.

We have started our important research in consideration of our experiences (Okamoto, Cristea \& Kayama 2001), and are gradually building the specified items towards a future standardization (ISO/IEC 2004). The considerations and issues we discussed in this paper are just the first steps towards standardization. Our future research directions are to provide a technical mechanism to reuse the learning logs (status, action history, snapshots and tag) for supporting CL and to realize the concept of epedagogy in this learning ecology.

\section{REFERENCES}

Cowie, H. and Ruddick, J. (1998) "Co-operative Group Work; an overview”, BP Educational Service, Sheffield University.

Dillenbourg, P. (1999). Collaborative learning - Cognitive and Computational Approaches" Pergamon.

ISO/IEC JTC1 SC36 WG2 (Collaborative Technologies): http:/collab-tech.jtclsc36.org/

Kayama M. \& Okamoto T. (2002) "Collaborative learning support in the internet learning space: a platform for a learning environment and knowledge management in the 
educational context", International Journal of Industry and Higher Education, Vol.16, No.4, pp.249-pp.259.

Okamoto T., Cristea A.I. \& Kayama M. (2001) Future integrated learning environments with Multimedia, Journal of Computer Assisted Learning (Ed. Robert Lewis), Blackwell Science, Vol.17, No.1, pp.3-12.

Okamoto, T., Cristea, A.I. and Kayama, M. (2000) "Towards Intelligent Media-Oriented Distance Learning and Education Environments", Proceedings of ICCE2000.

Roschelle, J. and Teasley, S.D. (1995) "The construction of shared knowledge in collaborative problem solving", In C.E. O'Malley (Ed.) Computer-Supported Collaborative learning, pp.69-97, Springer-Verlag.

UEC (2004) http:/www.ai.is.uec.ac.jp/ipa/ipa3/ 